Jurnal Akuntansi dan Bisnis : Jurnal Program Studi Akuntansi 7 (2) November 2021

ISSN 2443-3071 (Print) ISSN 2503-0337 (Online)

DOI: $10.31289 /$ iab.v7i2.5293

JURNAL AKUNTANSI DAN BISNIS

Jurnal Program Studi Akuntansi

Available online http://ojs.uma.ac.id/index.php/jurnalakundanbisnis

\title{
E-Procurement sebagai Upaya Pencegahan Fraud terhadap Pengadaan Barang dan Jasa di Unit Layanan Pengadaan Provinsi Sumatera Utara
}

\section{E-Procurement as an Effort to Prevent Fraud Against Procurement of Goods and Services in The Procurement Service Unit of North Sumatera Province}

\author{
Irine Ika Wardhani' ${ }^{1}$, Arifa Pratami² \& Ikbar Pratama ${ }^{3 *}$
}

1Fakultas Ekonomi dan Bisnis, Jurusan Akuntansi, Universitas Potensi Utama, Indonesia

${ }^{2}$ Fakultas Agama Islam, Universitas Islam Sumatera Utara, Indonesia

${ }^{3}$ Fakultas Ekonomi dan Bisnis, Universitas Medan Area, Medan, Sumatera Utara, Indonesia

Diterima: 28 Mei 2021 Direview: 28 Mei 2021 Disetujui: 05 September 2021

*Corresponding email: ikbarpratama@staff.uma.ac.id

\section{Abstrak}

Penelitian ini bertujuan untuk menganalisis pengaruh E-procurement, sistem pengendalian internal dan religiusitas terhadap pencegahan fraud pengadaan barang dan jasa pada Unit Layanan Pengadaan (ULP) Barang dan Jasa Provinsi Sumatera Utara. Penelitian ini menggunakan metode kuantitaf dengan sumber data primer yang diperoleh secara keseluruhan dari penyebaran kuisioner penelitian berjumlah 124 pada seluruh pegawai yang bekerja di ULP Provinsi Sumatera Utara. Analisis data pada penelitian ini menggunakan analisis Structural Equation Modelling (SEM) dengan menggunakan Partial Least Square (PLS). Hasil penelitian membuktikan bahwa variable e-procerement terbukti memiliki pengaruh yang signfikan positif terhadap pencegahan fraud pengadaan barang dan jasa. Variable relegiusitas terbukti memiliki pengaruh yang signfikan positif terhadap pencegahan fraud pengadaan barang dan jasa. Variable sistem pengendalian internal terbukti memiliki pengaruh yang signfikan positif terhadap pencegahan fraud pengadaan barang dan jasa.

Kata Kunci: Pencegahan Fraud; E-procurement; Relegiusitas

\section{Abstract}

This study aims to analyze the influence of E-procurement, internal control system and religiosity on the prevention of fraud procurement of goods and services in the Procurement Service Unit (ULP) of Goods and Services of North Sumatra Province. This study uses quantifiable method with primary data source obtained in its entirety from the spread of 124 research questionnaires on all employees working in ULP North Sumatra Province. Data analysis in this study using Structural Equation Modelling (SEM) analysis using Partial Least Square (PLS). The results prove that variable e-procerement is proven to have a positive impact on the prevention of fraud procurement of goods and services. Variable relegiusity is proven to have a positive impact on the prevention of fraud procurement of goods and services. Variable internal control system is proven to have a positive impact on the prevention of fraud procurement of goods and services.

Keywords: Fraud Prevention, E-Procurement; Religiosity

How to Cite: Wardhani, I. I. Pratami, A., \& Pratama, I., (2021). E-Procurement sebagai Upaya Pencegahan Fraud terhadap Pengadaan Barang dan Jasa di Unit Layanan Pengadaan Provinsi Sumatera Utara. Jurnal Akuntansi dan Bisnis: Jurnal Program Studi Akuntansi. 7 (2): 126-139 


\section{PENDAHULUAN}

Di era otonomi daerah, pengadaan barang dan jasa semakin tinggi. Hal ini dikarenakan pembangunan yang dilakukan daerah tidak terlepas dari kemampuan daerah untuk merencanakan dan menyediakan barang dan juga jasa. Tingginya kebutuhan daerah dalam penyediaan kebutuhan bagi masyarakat membuat beberapa oknum memanfaatkannya untuk kepentingan pribadi. Sebagaimana dinyatakan oleh Farida (2013) bahwa sistem yang beraku di Indonesia saat ini dalam hal penyediaan jasa dan barang masih menjadi ladang subur bagi praktik korupsi. Pendapat ini juga diperkuat oleh pendapat Ghani (2017) yang menyebutkan, bahwa pengadaan barang dan jasa merupakan penyumbang korupsi terbesar, hampir 80\% persoalan yang ditangani oleh Komisi Pemberantasan Korupsi (KPK) bersumber dari penyediaan barang dan juga jasa.

Kasus korupsi berupa kecurangan yang terjadi di Provinsi Sumatera Utara pada umumnya dalam penyediaan barang dan juga jasa, yang disebabkan oleh banyak faktor. Menurut Setyadiharja (2018) sedikitnya ada 10 faktor yang menyebabkan penyediaan barang dan juga jasa di lingkungan pemerintah rawan kecurangan antara lain : 1) Tender arisan dan adanya kickback pada proses tender. 2) Suap untuk memenangkan tender. 3) Proses tender yang tidak transparan. 4) Supplier bermain mematok harga tertinggi. 5) Memenangkan perusahaan saudara. 6) Pencantuman spesifikasi teknik hanya dapat dipasok oleh satu pelaku usaha tertentu. 7) Adanya almamater sentris, 8) Pengusaha tidak memiliki administrasi lengkap dapat ikut tender bahkan memenangkan tender, 9) Tender tidak diumumkan, 10) Tidak membuka akses bagi peserta dari daerah.

Dari 10 penyebab terjadinya tindakan korupsi dalam proses pengadaan barang dan jasa di atas maka setidaknya ada dua faktor yang menyebabkan kecurangan dalam pengadaan barang dan jasa yaitu faktor internal dan eksternal. Faktor internal seperti proses tender yang tidak transparan adanya memenangkan perusahaan saudara (oknum pegawai). Sedangkan untuk faktor eksternal, seperti pemasok menawar dengan harga tertinggi, dan pengusaha yang tidak memiliki hak pengelolaan penuh, mereka dapat mengikuti tender atau bahkan memenangkan tender. Untuk mengatasi berbagai permasalahan yang dihadapi pemerintah dalam proses pembelian barang dan jasa akan dimulai pada tahun 2012 pemerintah melalui Lembaga Kebijakan Pengadaan Pemerintah (LKPP) mengeluarkan surat edaran No 17/KA/02/2012 tentang kewajiban penyediaan barang maupun jasa secara elektronik. (Setyadiharja, 2018). Tujuan dari penyediaan barang maupun jasa secara online adalah untuk mengurangi pertemuan antara penyelenggara lelang barang maupun jasa dengan peserta. Menggunakan sistem pengadaan secara online atau E-procurenment maka proses penyediaan barang maupun jasa dapat berlangsung secara transparan dan akuntabel (Setyadiharja, 2018). Lebih lanjut Urumsah, Valoni, dan Asmu'i (2017) menyatakan jika pelaksanaan Eprocurenment pada dasarnya dilaksanakan sebagai satu upaya untuk mencegah terjadinya penyimpangan, termasuk didalamnya pada organisasi publik.

Provinsi Sumatera Utara salah satu daerah yang telah menerapakan sistem $E$ procurenment dalam implementasi penyediaan barang maupun jasa, dalam upaya melaksanakan E-procurenment maka pemerintah Provinsi Sumatera Utara juga telah membentuk suatu Unit Layanan Pengadaan (ULP). Adanya ULP ini semua penyediaan barang maupun jasa di lingkungan pemerintah Provinsi Sumatera Utara akan dikonsentrasikan pada satu unit pelayanan sehingga akan memberikan keefektifan dari segi biaya dan waktu, lebih akuntabel dalam pelaksanaan pengadaannya serta 
pertanggungjawabannya sebagaimana yang diamanatkan oleh Peraturan Presiden No.54 Tahun 2010 pasal 130. Pemanfaatan teknologi dalam penyediaan barang maupun jasa dalam bentuk E-procurenment ini diharapkan pemerintah kota/kabupaten dalam wilayah Provinsi Sumatera Utara dapat memperbaiki sistem penyediaan barang maupun jasa melalui pelaksanaan E-procurenment diharapkan mampu menutup terjadinya tindak kecurangan dalam proses penyediaan barang maupun jasa. Menurut Adi, Ardiyani dan Ardianingsih (2016) kecurangan merupakan suatu perbuatan yang bertentangan dengan hukum dan dilakukan oleh pihak internal maupun pihak eksternal organisasi, yang bertujuan untuk meraih keuntungan dan dapat menimbulkan kerugian pihak lain. Tuanakotta (2013) menyatakan jika kecurangan merupakan kejahatan yang dapat diatasi dengan dua cara, yaitu mencegah dan mendeteksi. Jadi pencegahan terhadap kecurangan merupakan diantara cara dalam menangani kecurangan.

Pada dasarnya penerapan E-procurement dapat mencegah timbulnya kecurangan. Hal ini disebabkan Sistem E-procurement dapat mengurangi intensitas pertemuan antara panitia pengadaan dengan penyedia jasa atau peserta, sehingga dapat menghindari praktek-praktek kotor yang seringkali mempengaruhi proses pembelian barang dan jasa Nedialita (2014). Selain dapat mencegah kecurangan, penerapan $E$ procurement menurut Urumsah et al (2017) juga akan diperoleh 6 keuntungan yaitu : 1) meningkatkan komunikasi, 2) mempererat hubungan dengan pihak supplier, 3) mengurangi biaya transaksi, 4) mengurangi waktu, 5) menyediakan laporan evaluasi dan 6) meningkatkan kepuasan pengguna. Penelitian yang telah dihasilkan oleh Isnaini et al., (2020); James dan Omulo (2018); Marbun et al., (2020); Nu'man et al., (2020); Nugroho et al., (2015); Nugroho et al., (2020); Saragih et al., (2020); Utami et al., (2019) Hasil penelitian menunjukkan bahwa sistem E-procurement memiliki pengaruh yang signifikan dan positif terhadap fraud dalam pengadaan barang/jasa. Jadi semakin baik dalam penerapan E-procurement semakin tinggi pula pencegahan terhadap fraud.

Kecurangan dalam proses penyediaan barang maupun jasa dipengaruhi oleh banyak faktor seperti pengendalian internal. Pengendalian internal menurut Hermiyetti (2010) adalah suatu tahapan yang dilakukan oleh dewan komisaris melaksanakan proses yang dirancang untuk memberikan jaminan yang memadai bagi realisasi pengendalian operasional yang efektif dan efisien, keandalan laporan keuangan, dan tujuan kepatuhan terhadap hukum dan peraturan yang berlaku. Pelaksanaan kontrol internal yang tepat dapat mencegah kecurangan. Hal ini sesuai yang telah diteliti oleh oleh Agyemang (2016); Danilwan et al., (2020); Oduro \& Cromwell (2018), Njenga \& Osiemo (2013), Mufidah (2017), Hermiyetti (2010) Joseph et al., (2015); Pratama et al., (2019); Rozmita et al., (2015); Saragaih et al., (2020); Sujianto et al., (2020) membuktikan jika pengendalian internal berdampak positif terhadap pencegahan kecurangan dalam penyediaan barang dan maupun jasa.

Faktor selanjutnya yang dapat mencegah tindakan kecurangan adalah relegiusitas. Secara khusus, Ahyadi (2015) menjelaskan bahwa religiusitas adalah bagaimana seorang individu memahami, menginternalkan dan mengintegrasikan norma-norma agama ke hidupan individu sehari-hari dan menjadi kepribadian mereka. Penelitian yang telah dihasilkan oleh Atrizka et al., (2020); Basri (2015) Purnamasari dan Amaliah, (2015) Wicaksono dan Urumsah (2016) membuktikan jika relegiusitas mampu mencegah kecurangan yang kan terjadi.

\section{Pengaruh E-procurement terhadap pencegahan fraud}

Croom dan Jones (2007) menjelaskan, E-procurement mengacu pada penggunaan kombinasi sistem teknologi informasi untuk fungsi pengadaan, termasuk pencarian 
sumber daya, negosiasi, pemesanan dan pembelian. Penerapan E-procurement pada dasarnya diimplementasikan dalam rangka mencegah timbulnya fraud. Hal ini disebabkan sistem E-procurement dapat mengurangi intensitas pertemuan antara panitia pengadaan dengan penyedia jasa atau peserta, sehingga dapat menghindari atau menghindari praktik-praktik kotor yang kerap mewarnai proses pembelian barang dan jasa. Nedialita (2014). Selain dapat mencegah kecurangan, penerapan E-procurement menurut Urumsah et al., (2017) juga akan diperoleh 6 keuntungan yaitu 1) meningkatkan komunikasi, 2) mempererat hubungan dengan pihak supplier, 3) mengurangi biaya transaksi, 4) mengurangi waktu, 5) menyediakan laporan evaluasi dan 6) meningkatkan kepuasan pengguna.

E-procurement adalah sistem yang dapat menyederhanakan proses pengadaan. Di era digital, pemerintah menggunakan internet untuk memberikan layanan dan untuk berkomunikasi dengan warga dan organisasi. Penerapkan pengadaan E-procurement menjadi lebi ringkas dan mudah dapat mengurangi korupsi (Rotchanakitumnuai, 2013). Pengadaan lelang elektronik memiliki peran utama dalam mengurangi kolusi dalam pengadaan dengan memperluas partisipasi dan memperluas pemasok atau perusahaan yang tertarik untuk bergabung dengan pengadaan (Rotchanakitumnuai, 2013). Hasil penelitian yang dilakukan oleh James \& Omulo (2018) Nugroho et al., (2015) menunjukkan bahwa Hasil penelitian menunjukkan bahwa sistem E-procurement memiliki pengaruh yang signifikan dan positif terhadap fraud dalam pengadaan barang maupun jasa. Jadi semakin baik dalam penerapan E-procurement semakin tinggi pula pencegahan terhadap fraud. Maka, dari uraian di atas maka hipotesis yang akan dirumuskan adalah sebagai berikut:

\section{H1: E-procurement berpengaruh positif terhadap pencegahan fraud}

\section{Pengaruh Relegiusitas dengan Pencegahan Fraud}

Ahyadi (2015) menjelaskan bahwa religiusitas adalah bagaimana seseorang individu memahami, menginternalkan dan mengintegrasikan norma-norma agama menjadi prilaku dan menjadi kepribadian mereka. Relegiusitas atau agama mampu menjadi tameng untuk melindungi perilaku seseorang dalam melakukan tindakan yang bertentangan dengan nilai-nilai yang diyakininya. Orang dengan sikap religius yang tinggi cenderung berperilaku etis dan menghindari kecurangan. Keimanan yang kokoh diharapkan dapat mencegah perilaku untuk melakukan tindakan yang bertentangan dengan apa yang diyakininya, akan terasa bersalah ketika melakukan kecurangan (Basri, 2015).

Pemahaman yang baik tentang relegiusitas seseorang akan diimplementasikan dan tercermin dalam prilaku dan sikap dalam berbagai kegiatan termasuk dalam bekerja. Keyakinan bahwa Tuhan ada menyebabkan seseorang akan secara konsisten dengan aturan manusia dan aturan Tuhan termasuk untuk melakukan kecurangan. Karena itu, pemahaman yang tinggi tentang relegiusitas akan menyebabkan rendahnya tidakan untuk melakukan kecurangan, karena merupakan sesuatu yang dilarang oleh agama. Hasil penelitian yang ditulis oleh Purnamasari dan Amaliah, (2015) Wicaksono dan Urumsah (2016) dan Basri (2015) membuktikan jika relegiusitas mampu membentengi diri untuk tidak melakukan tindakan kecurangan. Maka dari uraian ini hipotesis yang akan diajukan adalah sebagai berikut:

\section{H2: Relegiusitas berpengaruh positif terhadap pencegahan fraud}




\section{Pengaruh Sistem Pengendalian Internal terhadap Pencegahan Fraud.}

Hermiyetti (2010) menyatakan bahwa pengendalian internal adalah proses yang dilakukan oleh dewan komisaris yang bertujuan untuk memberikan jaminan yang cukup bagi terwujudnya tujuan pengendalian operasional yang efektif dan efisien, keandalan laporan keuangan, dan kepatuhan terhadap peraturan perundang-undangan yang berlaku. Pelaksanaan kontrol internal yang tepat dapat mencegah tindakan penipuan. Jadi sistem pengkontrolan yang efektif pada akhirnya dapat menutup seseorang akan melakukan kecurangan dalam hal ini adalah kecurangan dalam penyediaan barang dan maupun jasa.

Penelitian yang dilakukan oleh Oduro \& Cromwell (2018), Njenga \& Osiemo (2013), Agyemang (2016), Mufidah (2017), Hermiyetti (2010) Joseph et al., (2015), Rozmita et al., (2015) membuktikan jika pengendalian internal berdampak positif terhadap pencegahan kecurangan dalam penyediaan barang dan maupun jasa. Berdasarkan uraian ini maka hipotesis yang akan diajukan adalah sebagai berikut:

\section{H3: Sistem pengendalian internal berpengaruh positif terhadap pencegahan fraud}

\section{Data Collection and Methods}

\section{METODE PENELITIAN}

Metode pengumpulan data pada penelitian ini adalah menggunakan kuesioner. Kuesioner menurut Sukmadinata (2008) adalah suatu teknik atau cara dalam mengumpulkan data peneltian secara tidak langsung, karena peneliti tidak bertanya dan responden kemudian menjawab. Kuesioner dalam penelitian ini berbentuk kuesioner tertutup. Seluruh pertanyaan penelitian menggunakan Likert Scale. Sangat Tidak Setuju (1), Tidak Setuju (2), Agak Tidak Setuju (3), Agak Setuju (4), Setuju (5) dan Sangat Setuju (6). Penelitian ini menggunakan data primer yang diperoleh secara keseluruhan dari penyebaran kuisioner penelitian berjumlah 124 pada seluruh pegawai yang bekerja di ULP Provinsi Sumatera Utara.

\section{Variables Definition and Measurements}

Pencegahan fraud merupakan merupakan suatu perbuatan untuk mencegah timbulnya kegiatan yang bertentangan dengan hukum dan dilakukan oleh orang internal ataupun luar organisasi dan dapat menimbulkan kerugikan pihak lain. Pencegahan fraud pada penelitian ini diukur dengan indikator-indikator yang ditawarkan oleh Albrecht dan Albrecht (2009).

E-procurement mengacu pada penggunaan sistem teknologi informasi terintegrasi untuk fungsi pengadaan, termasuk pencarian sumber daya, negosiasi, pemesanan dan pembelian. E-Procurement dalam penelitian ini mengacu pada pendapat Nugroho et al., (2015). Religiusitas adalah bagaimana seorang individu memahami, menginternalkan dan mengintegrasikan norma-norma agama menjadi prilaku dan kepribadian mereka. Relegiusitas pada penelitian ini dukur dengan indiaktor yang ditawakan oleh (Robbins, Glock, \& Stark, 1994).

Pengendalian internal adalah proses yang dilakukan oleh direksi yang bertujuan untuk memberikan kepastian yang cukup bagi terwujudnya tujuan pengendalian operasional yang efektif dan efisien, keandalan laporan keuangan dan kepatuhan terhadap peraturan perundang-undangan yang berlaku. Pada penelitian ini 
pengendalian internal merujuk pada indikator-indiaktor yang ditawarkan oleh (Oduro \& Cromwell, 2018).

\section{Modelling and Methodological Framework}

Untuk menganalisis data penelitian ini akan menggunakan analisis SEM (Structural Equation Modelling) dengan menggunakan (PLS) Partial Least Square (PLS) sebagai alat menganalisis. PLS merupakan diantara metode yang digunakan untuk melaksanakan SEM (model Structural Equation Modelling). Untuk tujuan penelitian ini metode ini dirasa lebih baik dibandingkan software SEM yang lain, misalnya AMOS dan LISREL. Model PLS ini akan digunakan jika landasan teori perancangan model lemah dan indikator pengukuran tidak sesuai dengan model pengukuran ideal. PLS dapat digunakan untuk sejumlah kecil sampel dan dapat diterapkan pada semua skala data (Ghozali dan Latan, 2012).

\begin{tabular}{cc} 
& Tabel 1 Kriteria Penilaian PLS \\
\hline Kriteria & Penjelasan \\
\hline Evaluasi model & Nilai loading faktor diatas 0,6 \\
Pengukuran & Composite reliability $>0,60$. \\
& AVE $>0,50$ \\
& Cronbachs Alpha $>0,70$ \\
\hline Evaluasi model & $\mathrm{P}_{\text {value }}<0,05$. \\
Struktural & $\boldsymbol{f}^{2}$ dan $q^{2}$ \\
& 0,02 small Effect \\
& 0,15 medium Effect \\
0,35 large Effect
\end{tabular}

\section{Descriptive Statistics}

\section{HASIL DAN PEMBAHASAN}

Analisis deskriptif pada penelitian ini akan dilakukan dengan cara mendeskrisikan data setiap variabel seperti rata-rata (mean), nilai minimum, nilai maksimum dan standar deviasi serta penyajian data melalui tabel frekuensi.

Tabel 2 Deskripsi Variabel

\begin{tabular}{cccccc}
\hline & N & Minimum & Maximum & Mean & Std. Deviation \\
\hline Pencegahan Fraud & 124 & 3.00 & 5.50 & 4.42 & 0.55 \\
E-Procurement & 124 & 3.00 & 6.00 & 4.41 & 0.54 \\
SPI & 124 & 2.20 & 6.00 & 4.49 & 0.69 \\
Relegiusitas & 124 & 3.00 & 5.80 & 4.43 & 0.62 \\
\hline
\end{tabular}

Sumber: Data Primer (2020)

Dari tabel 2 dapat diketahui jika variabel pencegahan Fraud memiliki rata-rata 4,42 yang termasuk ke dalam kategori baik. Variabel E-procurement 4,41 yang termasuk ke dalam kategori baik. Demikian halnya dengan variabel relegiusitas yang secara rata-rata dalam kategori baik.

\section{Uji Indikator}

Disebut juga outer model adalah menguji hubungan antara indikator terhadap variabel konstruknya. Dari uji indikator ini diperoleh output validitas dan realibilitas model yang diukur dengan kriteria Convergent Validity, Discriminant Validity, dan Composite Reliability. Hasil convergent validity seperti yang disajikan pada Tabel 3. 
Irine Ika Wardhani, Arifa Pratami \& Ikbar Pratama. E-Procurement sebagai Upaya Pencegahan

Tabel 3 Item Loading dan Average Variance Expected (AVE)

\begin{tabular}{|c|c|c|c|c|}
\hline Variabel & Item pernyataan & Kode & Loading & AVE \\
\hline \multirow{6}{*}{$\begin{array}{l}\text { Pencegahan } \\
\text { Fraud }\end{array}$} & Menolak penggunaan dokumen fotokopian & PF1 & 0,966 & \multirow{6}{*}{0,886} \\
\hline & Terdapat pemisahan fungsi dan tanggung jawab yang jelas & PF2 & 0,849 & \\
\hline & Menghindari praktik-praktik yang tidak lazim/mencurigakan & PF3 & 0,948 & \\
\hline & Ada larangan gaya hidup mewah & PF4 & 0,948 & \\
\hline & Ada rasa bersalah dan ketakutan & PF5 & 0,966 & \\
\hline & Menyediakan sarana pengaduan & PF6 & 0,962 & \\
\hline \multirow{5}{*}{ E-procurement } & Implementasi E-procurement dapat mengurangi biaya & EE1 & 0,806 & \multirow{5}{*}{0,697} \\
\hline & $\begin{array}{l}\text { Implementasi E-procurement menyebabkan perubahan } \\
\text { perilaku }\end{array}$ & EE2 & 0,836 & \\
\hline & $\begin{array}{l}\text { Implementasi E-procurement terjadi pergeseran hubungan, } \\
\text { peningkatan pertukaran informasi antara panitia pengadaan } \\
\text { dengan calon penyedia }\end{array}$ & EE3 & 0,857 & \\
\hline & $\begin{array}{c}\text { Implementasi E-procurement memudahkan dalam } \\
\text { perencanaan dan pengendalian }\end{array}$ & EE4 & 0,895 & \\
\hline & $\begin{array}{c}\text { Implementasi E-procurement dapat meningkatkan } \\
\text { produktivitas dan mengurangi biaya }\end{array}$ & EE5 & 0,773 & \\
\hline \multirow{5}{*}{$\begin{array}{l}\text { Sistem } \\
\text { Pengendalian } \\
\text { Internal }\end{array}$} & $\begin{array}{c}\text { Lingkungan pengendalian merupakan dasar untuk semua } \\
\text { komponen pengendalian }\end{array}$ & SPI1 & 0,884 & \multirow{5}{*}{0,806} \\
\hline & $\begin{array}{l}\text { Membentuk suatu dasar untuk menentukan bagaimana risiko } \\
\text { harus dikelola }\end{array}$ & SPI2 & 0,907 & \\
\hline & $\begin{array}{c}\text { Kebijakan dan prosedur yang membantu menjamin bahwa } \\
\text { arahan manajemen dilaksanakan }\end{array}$ & SPI3 & 0,916 & \\
\hline & $\begin{array}{c}\text { Penentuan desain dan operasi pe ngendalian tepat waktu dan } \\
\text { pengambilan tindakan perbaikan }\end{array}$ & SPI4 & 0,876 & \\
\hline & $\begin{array}{c}\text { Model penyampaian informasi kepada semua yang } \\
\text { bertanggungjawab }\end{array}$ & SPI5 & 0,904 & \\
\hline \multirow{5}{*}{ Relegiusitas } & Tingkat kepercayaan individu terhadap nilai-nilai agama & RG1 & 0,875 & \multirow{5}{*}{0,772} \\
\hline & $\begin{array}{c}\text { Tingkat kepatuhan individu dalam melakukan ritual kegiatan } \\
\text { seperti yang diperintahkan }\end{array}$ & RG2 & 0,881 & \\
\hline & Tingkat perasaan dan pengalaman religius individu & RG3 & 0,817 & \\
\hline & $\begin{array}{c}\text { Tingkat pengetahuan dan pemahaman individu } \\
\text { nilai agama mereka }\end{array}$ & RG4 & 0,784 & \\
\hline & $\begin{array}{c}\text { Tingkat perilaku individu yang dimotivasi oleh } \\
\text { mereka agama }\end{array}$ & RG5 & 0,885 & \\
\hline
\end{tabular}

Hasil uji indikator pada Tabel 3 di atas menunjukkan bahwa semua indikator variabel memiliki nilai loading yang lebih besar dari 0,60. Hasil Average Variance Expected (AVE) semua variabel juga memiliki yang lebih besar dari 0,50, dengan demikian semua indikator penelitian dapat dinyatakan valid dan dapat digunakan untuk digunakan dalam melakukan analisis data.

\section{Uji Hipotesis (Inner Model)}

Berdasarkan pengujian dengan menggunakan Smart PLS.2 diperoleh hasil sebagaimana pada Gambar 1 diperoleh hasil sebagai berikut: 


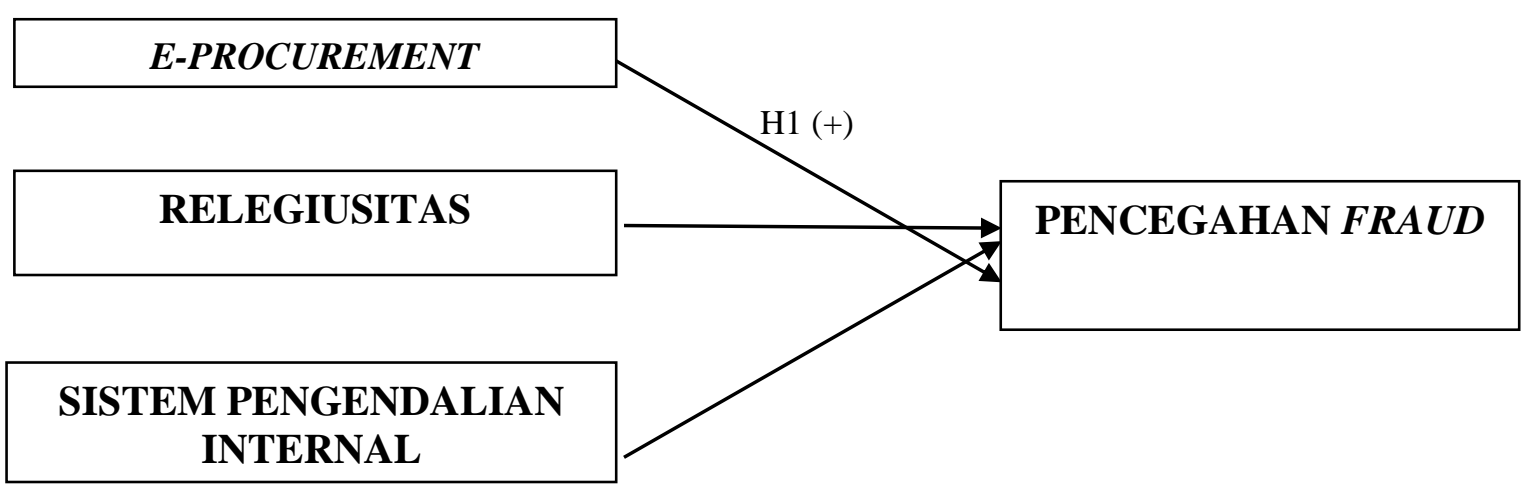

Gambar 1 Hasil Uji Hipotesis

Tabel 4 Koefisien Parameter, R Square, dan T-Statistik

\begin{tabular}{|c|c|c|c|c|c|c|}
\hline Hipotesis & Hubungan & $\begin{array}{c}\beta \\
\text { (Beta) }\end{array}$ & $\begin{array}{c}\text { R } \\
\text { Square }\end{array}$ & $\begin{array}{c}\mathbf{T} \\
\text { Statistics }\end{array}$ & Kesimpulan & Keterangan \\
\hline H1 & EE -> PF & 0,217 & \multirow{3}{*}{0,957} & 3,567 & Signifikan & Sesuai Hipotesis \\
\hline H2 & RG -> PF & 0,158 & & 2,213 & Signifikan & Sesuai Hipotesis \\
\hline H3 & SPI -> PF & 0,148 & & 2,072 & Signifikan & Sesuai Hipotesis \\
\hline
\end{tabular}

Sumber: Data primer diolah, 2020

Goodness of fit model diukur menggunakan R-square variabel laten dependen dengan interpretasi yang sama dengan regresi. Korelasi prediksi Q-square model struktural adalah ukuran nilai observasi yang dihasilkan oleh model dan derajat estimasi parameter. Nilai R-square $>0$ artinya jika nilai R-square sama dengan 0 , model memiliki korelasi prediktif yang berlawanan. 0 berarti bahwa model tidak memiliki korelasi prediktif. Nilai R-square 0.957 dapat diartikan bahwa variabel independen (PF, SPI, dan RG dapat menjelaskan Y (PF) sebesar 95,7\%.

Tabel 4 menunjukkan bahwa E-procurement memiliki t statistik 3,567 > 1,96, dengan demikian variabel E-procurement terbukti secara statistik memiliki pengaruh yang signifikan dan positif terhadap pencegahan fraud, dengan demikian semakin baik penerapan E-procurement maka akan semakin baik pula pencegahan fraud yang dilakukan oleh pegawai ULP Sumatera Utara. Sistem Pengendalian Internal memiliki t statistik 2,072 >1,96, dengan demikian variabel Sistem Pengendalian Internal terbukti secara statistik memiliki pengaruh yang signifikan dan positif terhadap pencegahan fraud. Relegiusitas memiliki $t$ statistik 2,213 $>1,96$, dengan demikian variabel relegiusitas terbukti secara statistik memiliki pengaruh yang signifikan dan positif terhadap pencegahan fraud.

\section{Pengaruh E-procurement terhadap Pencegahan Fraud}

Croom dan Jones (2007) menjelaskan, E-procurement mengacu pada penggunaan kombinasi sistem teknologi informasi untuk fungsi pengadaan, termasuk pencarian sumber daya, negosiasi, pemesanan dan pembelian. Penerapan E-procurement pada dasarnya diimplementasikan dalam rangka mencegah timbulnya fraud. Hal ini disebabkan sistem pengadaan secara elektronik dapat mengurangi intensitas pertemuan antara panitia pengadaan dengan penyedia jasa atau peserta, sehingga dapat 
mencegah atau menghindari praktek-praktek kotor yang kerap mewarnai proses pengadaan barang dan jasa. Nedialita (2014).

Konsep fraud triangle theory kecurangan dalam penyediaan barang maupun jasa disebabkan karena adanya peluang (opportunity). Berkatian dengan E-procurement maka dapat meminimalisir peluang (opportunity) untuk malakukan kecurangan. Hal Ini karena penipuan tidak hanya terjadi dalam situasi tekanan, tetapi juga ketika penipu menemukan peluang untuk melakukan penipuan. Terdapat beberapa faktor utama yang dapat meningkatkan peluang untuk mendorong seseorang melakukan kecurangan, yaitu 1) kurangnya tindakan pengendalian untuk mencegah dan mendeteksi perilaku abnormal dan 2) ketidakmampuan menilai kualitas kinerja dengan baik. 3) Kegagalan menghukum pelaku penipuan. 4) Kurangnya informasi. 5) Ketidak perdulian, dan ketidak mampuan. 6) Kurangnya jejak audit (Iqbal dan Murtanto, 2016). Pada dasarnya, sistem pengadaan barang dan jasa secara elektronik di Sumatera Utara telah berperan positif dalam mencegah terjadinya fraud.

Hasil penelitian ini membuktikan bahwa penggunaan E-procurement untuk pelaksanaan pengadaan barang dan jasa di Sumatera Utara terbukti berdampak signifikan terhadap pencegahan kecurangan. Pemanfaatan E-procurement dalam proses penyediaan barang maupun jasa dapat mencegah fraud karena dalam prosesnya intensitas pertemuan antara panita penyediaan barang maupun jasa dengan calon vendor sangat minim sehingga peluang panita penyediaan barang maupun jasa untuk melakukan kecurangan dapat dihindari (Nedialita, 2014). Calon vendor dan panitia dalam selama proses tidak saling bertemu atau berkonomunikasi sehingga peluang untuk melakukan "suap", oleh calon vendor yang sering terjadi dalam proses penyediaan barang maupun jasa secara manual, dengan demikian sistem E-procurement dalam penyediaan barang maupun jasa menyebabkan proses dapat berjalan trasparan dan dapat menghilangkan potensi adanya kecurangan.

Hasil dari penelitian ini mendukung hasil penelitian sebelumnya seperti penelitian yang dilakukan oleh Nugroho et al. (2015) menunjukkan bahwa sistem E-procurement memiliki pengaruh yang signifikan dan memiliki arah positif terjadinya fraud dalam pengadaan barang dan jasa. Jadi semakin baik dalam penerapan E-procurement semakin tinggi pula pencegahan terhadap fraud.

Pada kenyatannya meskipun keberadaan sistem E-procurement dapat dilakukan dalam proses pembelian barang dan jasa dapat membantu mencegah terjadinya fruad, namun jika tidak dimanfaatkan dengan efektif dan efisien E-procurement tidak akan berfungsi dengan baik. Pemerintah dalam hal ini harus menyelaraskan semua instansi untuk menerapkan sistem E-procurement dalam pengadaan barang dan jasa berdasarkan Undang-Undang yang telah disahkan mengenai proses penyedian barang maupun jasa secara online. ULP Provinsi Sumatera Utara dapat melakukan pelatihan bagi seluruh pegawai untuk mengenalkan proses pelaksanaan E-procurement agar sumber daya dapat menunjang sistem.

\section{Pengaruh Relegiusitas dengan Pencegahan Fraud}

Hasil penelitian membuktikan jika ada pengaruh yang signifikan antara relegiusitas dengan pencegahan fraud. Purnamasari dan Amaliah (2015) menjelaskan bahwa religiusitas adalah bagaimana seorang individu memahami, menginternalkan dan mengintegrasikan norma-norma agama kedalam prilaku dan menjadi kepribadian mereka. Sementara itu menurut Pamungkas (2014) religiusitas merupakan kepercayaan, gaya hidup, aktivitas ritual dan lembaga penyedia yang komprehensif makna dalam kehidupan manusia dan mengarahkan manusia pada nilai-nilai suci. 
Adapun Pamungkas (2014) agama sebagai komitmen, beragama dapat dilihat melalui aktivitas atau perilaku individu yang berhubungan dengan agama atau kepercayaan.

Setiap ULP di Sumatera Utara memiliki cara masing-masing untuk meningkatkan relegiusitas para pegawai mereka (Adhim, 2009). Pengamalan terhadap kepercayaan yang dianut oleh setiap pegawai harus diwujudkan secara nyata dalam melaksanakan pekerjaan. Bagi karyawan yang bergama Islam ada kajian khusus yang dilaksanakan secara rutin. Kajian ini dimaksudkan agar mereka dapat meresapi ajaran agama mengenai kejujuran dalam bekerja dan takut jika melakukan kecurangan dalam proses pengadaan barang dan jasa.

Ahyadi (2015) menjelaskan bahwa religiusitas adalah bagaimana seorang individu memahami, menginternalkan dan mengintegrasikan norma-norma agama kedalam prilaku dan menjadi kepribadian mereka. Relegiusitas atau agama diyakini mampu mengendalikan tingkah laku seseorang sehingga bertentangan dengan nilai-nilai yang dianutnya. Orang dengan sikap religius yang tinggi cenderung berperilaku etis dan menghindari kecurangan. Keyakinan agama yang kuat diharapkan dapat mencegah orang mengambil kesalahan dan bertindak bertentangan dengan apa yang mereka pikirkan, terutama dalam penipuan. Keyakinan agama yang kuat diharapkan dapat mencegah orang melakukan tindakan yang bertentangan dengan apa yang dipikirkannya melalui rasa bersalah, terutama dalam penipuan (Basri, 2015).

Hasil penelitian ini sejalan dengan hasil penelitian yang dilakukan oleh Purnamasari dan Amaliah (2015), Wicaksono dan Urumsah (2016), dan Basri (2015) membuktikan jika relegiusitas dapat mencegah terjadinya kecurangan, dengan demikian keteguhan pegawai ULP Provinsi Sumatera Utara dengan agama yang dianutnya dapat meningkatkan kemauan mereka untuk mencegah terjadinya kecurangan dalam penyediaan barang maupun jasa.

Relegiusitas berkaitan dengan karakteristik setiap individu dan tidak dapat dilihat dengan mata. Relegiusiatas pegawai bukan hanya pelaksanaan kewajiban seseorang dalam melaksanakan perintah agamanya masing-masing. Perintah dari agama bukan hanya bersifat ritualistik namun juga dalam bentuk perbuatan. Seseorang mungkin dapat dinyatakan orang yang relegius karena selalau melaksanakan shalat bagi yang muslim, datang ke gereja setiap hari minggu bagi yang nasrani. Akan tetapi ketika melaksanakan pekerjaan nilai relegiusitas tersebut tidak diwujudkan salah satunya adalah dengan melakukan kecurangan (Hariyanto, Rini, \& Margianawati, 2018). Padahal agama manapun tidak ada yang memerintahkan umatnya untuk melakukan perbuatan yang merugikan orang lain.

Jadi untuk mengimplentasikan relegiusitas seseorang menjadi tindakan dalam melaksanakan pekerjaan maka diperlukan penanaman nilai-nilai relegiutas dalam bekerja (Rifa'i, 2016). Maka dari itu setiap ULP di Sumatera Utara perlu membuat program yang dapat meningkatkan relegiusitas pegawai seperti kajian rutin setiap jum'at dengan mengundang tokoh agama tertentu, mengadakan kegiatan agama dan lain sebagainya. Program-program tersebut perlu dilakukan dalam upaya meningkatkan pemahaman pegawai mengenai nilai-nilai relegiusitas dalam bekerja.

\section{Pengaruh Sistem Pengendalian Internal terhadap Pencegahan Fraud}

Hermiyetti (2010) mengemukakan bahwa pengendalian internal merupakan proses yang dilakukan oleh dewan komisaris, yang bertujuan untuk memberikan jaminan yang cukup bagi terwujudnya tujuan pengendalian operasional yang efektif dan efisien, keandalan laporan keuangan, dan kepatuhan. Mematuhi hukum dan peraturan. 
Pelaksanaan kontrol internal yang tepat dapat mencegah penipuan. Jadi sistem pengendalian yang baik pada akhirnya dapat menutup sesorang akan melakukan kecurangan dalam hal ini adalah kecurangan dalam penyediaan barang maupun jasa.

Dalam konsep fraud triangle theory kecurangan dalam penyediaan barang maupun jasa disebabkan karena adanya, peluang (opportunity), tekanan (pressure) dan rasionalisasi, dengan demikian sistem pengendalian internal dalam penyediaan barang maupun jasa dapat mencegah terjadinya kecurangan. Peluang, tekanan, rasionalisasi dapat hilang jika organisasi menerapakan sistem pengendalian internal dengan baik. Meskipun dalam sistem pengendalian internal masih ada potensi untuk terjadinya kolusi, namun hasil penelitian membuktikan bahwa aktivitas pengendalian yang di lakukan oleh ULP Provinsi Sumatera Utara sudah baik. Pimpinan melakukan pengawasan secara ketat dalam proses pengadaan barang dan jasa, seperti petugas tidak diperkenankan melakukan pertemuan dengan calon vendor dengan alasan apapun, pimpinan juga melakukan pengwasan terhadap calon vendor yang terindikasi memiliki hubungan kekerabatan dengan panitia pengadaan barang dan jasa.

Hasil penelitian ini membuktikan jika ada pengaruh yang signifikan antara sistem pengendalian internal dengan pencegahan fraud. Hasil penelitian mendukung hasilhasil penelitian sebelumnya seperti penelitian yang dilakukan oleh Mufidah (2017), Hermiyetti (2010) Joseph et al (2015), Rozmita et al (2015) yang juga membuktikan jika pengendalian internal berdampak positif terhadap pencegahan kecurangan dalam pengadaan barang dan jasa.

Sistem pengendalian internal yang efektif merupakan faktor utama untuk dapat mendeteksi dan mencegah jika adanya aktivitas peyimpangan yang akan berakibat pada kerugian pemerintah. Adapun untuk membangun sistem pengendalian internal yang efektif dan efisien di ULP Provinsi Sumatera Utara harus ada komitmen dari semua pegawai dari tataran manajeman maupun pegawai biasa seperti penyampain informasi yang memadai. Hal ini dikarenakan tanpa adanya komitmen dari semua pihak sistem pengendalian internal tidak akan berjalan dengan baik.

Guna mewujudukan komitmen dalam menerapkan sistem pengendalian internal tersebut, pemerintah daerah perlu untuk memberikan sanksi tegas bagi para top manajemen ULP yang tidak melakukan sistem pengendalian internal. Selain sanksi reward juga perlu diberikan bagi mereka yang telah menjalankan sistem pengendalian internal dengan baik (Faisol, Tarjo, \& Musyarofah, 2014). Selain menggunakan sanksi dan reward untuk menjamin pelaksanaan dari sistem pengendalian internal, cara lain yang dapat digunakan adalah pelaksanaan sidak secara konsisten. Hal ini perlu dilakukan agar proses pengadaan barang dan jasa di ULP semakin baik dan juga terbebes dari kecurangan.

\section{SIMPULAN}

E-procurement merupakan variabel yang berdampak positif terhadap pencegahan terjadinya kecurangan. Dari hasil ini maka pemerintah dalam hal ini ULP dapat memanfaatkan sistem E-procurement dalam proses pengadaan barang dan jasa karena dapat mencegah terjadinya kecurangan. Selain dapat mencegah kecurangan, penerapan E-procurement menurut Urumsah et al., (2017) juga akan diperoleh 6 keuntungan yaitu 1) meningkatkan komunikasi, 2) mempererat hubungan dengan pihak supplier, 3) mengurangi biaya transaksi, 4) mengurangi waktu, 5) menyediakan laporan evaluasi dan 6) meningkatkan kepuasan pengguna. Sistem pengendalian internal yang dilaksanakan dapat dicegah dengan tepat, karena pengendalian internal dapat membuat proses operasional menjadi efektif dan efisien, pelaporan keuangan yang dapat 
diandalkan dan kepatuhan terhadap peraturan perundang-undangan yang berlaku. Hasil penelitian membuktikan jika sistem pengendalian internal memiliki pengaruh yang signifikan positif terhadap pecegahan fraud. Dari hasil ini maka pemerintah dalam hal ini ULP selain pemanfaatan E-procurement juga diperlukan sistem pegendalian internal yang baik, sehingga celah untuk melakukan fraud dalam proses pengadaan barang dan jasa dapat ditutupi. Hermiyetti (2010) menyatakan jika pengendalian internal merupakan suatu proses yang dijalankan oleh dewan komisaris yang ditujukan untuk memberikan keyakinan yang memadai tentang pencapaian tujuan pengendalian operasional yang efektif dan efisien, keandalan laporan keuangan, dan kepatuhan terhadap hukum dan peraturan yang berlaku. Pengendalian internal yang dilakukan dengan baik dapat mencegah tindakan kecurangan. Jadi sistem pengendalian yang baik pada akhirnya dapat menutup seseorang akan melakukan kecurangan dalam hal ini adalah kecurangan dalam pengadaan barang dan jasa. Hasil penelitian membuktikan bahwa relegiusitas pegawai memiliki pengaruh yang positif dan signifikan terhadap pencegahan fraud. Dengan demikian upaya yang dapat dilakukan ULP dalam upaya melakukan pencegahan fraud dapat dilakukan dengan menyelenggarakan kajian-kajian rohani para pegawainya sesuai dengan kepercayaannya masing-masing. Hal ini diperlukan agar setiap pegawai memiliki relegiusitas yang baik, sehingga keinginannya untuk melakukan kecurangan dapat berkurang. Ahyadi (2015) menjelaskan bahwa religiusitas adalah bagaimana seseorang individu memahami, menginternalkan dan mengintegrasikan norma-norma agama ke dalam diri mereka dan menjadi kepribadian mereka. Relegiusitas atau agama dipercaya dapat mengontrol perilaku seseorang dalam melakukan tindakan yang bertentangan dengan nilai-nilai yang diyakininya. Seseorang yang memiliki sikap religiusitas yang tinggi cenderung berperilaku etis dan menghindari perilaku untuk melakukan kecurangan.

\section{Implications of the study}

Dari hasil ini maka pemerintah dalam hal ini ULP dapat memanfaatkan sistem Eprocurement sedang dalam proses pembelian barang dan jasa karena dapat mencegah terjadinya penipuan. Selain pemanfaatan E-procurement juga diperlukan sistem pegendalian internal yang baik, sehingga celah untuk melakukan fraud dalam proses penyediaan barang maupun jasa dapat ditutupi. Hasil penelitian membuktikan bahwa relegiusitas pegawai memiliki pengaruh yang positif dan signifikan terhadap pencegahan fraud, dengan demikian upaya yang dapat dilakukan ULP dalam upaya melakukan pencegahan fraud dapat dilakukan dengan menyelenggarakan kajian-kajian rohani para pegawainya sesuai dengan kepercayaannya masing-masing. Hal ini diperlukan agar setiap pegawai memiliki relegiusitas yang baik, sehingga keinginannya untuk melakukan kecurangan dapat berkurang.

\section{Limitations and future research indications}

Keterbatasan dalam penelitian ini adalah variabel independen yang di analisis hanya E-procurement, sistem pengendalian internal, budaya organisasi, etika pegawai dan relegiusitas pegawai sebagai variabel-variabel yang dapat mempengaruhi pencegahan fraud. Padahal masih ada variabel lain lain yang dapat mempengaruhi pencegahan fraud seperti komitmen organisasi, motivasi kerja dan peran kepemimpinan.

Adapun saran yang penyusun tawarkan diataranya adalah terkait dengan pencegahan fraud yang perlu diperhatikan adalah penggunaan dokumen. Hal ini 
dikarenakan pernyataan akan menolak untuk menggunakan dokumen fotokopian mendapatkan skor yang paling kecil. Saran lainnya adalah berkaitan dengan etika pegawai ada beberapa hal yang perlu diperhatikan oleh pimpinan ULP di Seluruh Provinsi Sumatera Utara adalah pegawai tidak menerima dan memberi imbalan dan selalu menjaga kerahasiaan dan mencegah penyalahgunaan data dan informasi elektronik.

Kedua hal ini perlu mendapat perhatian lebih karena mendapatkan skor yang paling rendah diantara komponen lainnya. Sementara itu berkaitan dengan budaya organisasi ULP Provinsi Sumatera Utara dapat melakukan perubahan dalam mekanisme kerja, untuk memudahkan pegawai dengan mencegah terjadinya fraud.

\section{DAFTAR PUSTAKA}

Adi, M. R. K., Ardiyani, K., \& Ardianingsih, A. (2016). Analisis Faktor-Faktor Penentu Kecurangan (Fraud ) (Studi Kasus Pada Dinas Pendapatan Pengelolaan Keuangan dan Aset Daerah Kota Pekalongan). Jurnal Litbang Kota Pekalongan, 10, 1-10.

Agyemang, J. K. (2016). Internal Control and Fraud Prevention. International Journal of Management and Scientific, 3(1), 2-12.

Ahyadi, A. (2015). Psikologi agama: kepribadian muslim Pancasila. Ba: Sinar Baru. Retrieved from https://scholar.google.com/scholar?q=muslim+psikologi\&btnG=\&hl=en\&as_sdt=0\%2C5\#0

Atrizka, D., Lubis, H., Simanjuntak, C. W., \& Pratama, I. (2020). Ensuring Better Affective Commitment and Organizational Citizenship Behavior through Talent Management and Psychological Contract Fulfillment: An Empirical Study of Indonesia Pharmaceutical Sector. Systematic Reviews in Pharmacy, 11(1), 545-553.

Basri, Y. M. (2015). Pengaruh dimensi budaya dan religiusitas terhadap kecurangan pajak.

Chawla, D., \& Joshi, H. (2018). Consumer attitude and intention to adopt mobile wallet in India - An empirical study. International Journal of Bank Marketing, 37(7), 1590-1618.

Croom, S., \& Brandon-jones, A. (2007). Impact of e- procurement: Experiences from implementation in the UK public sector. Journal of Purchasing and Supply Management, 13(4), 294-303.

Danilwan, Y., Dirhamsyah., Pratama, I. (2020). The Impact of Consumer Ethnocentrism, Animosity And Product Judgment On The Willingness To Buy. Polish Journal of Management Studies 2020; 22 (2): 65-81.

Farida, N. (2013). Kinerja unit layanan pengadaan barang / jasa di sekretariat daerah kabupaten banjar. Jurnal Ilmu Politik Dan Pemerintahan Lokal, II(1), 143-163.

Ghani, R. (2017). Ini Celah Kecurangan Pengadaan Barang dan Jasa yang Berpotensi Korupsi. Retrieved from https://eproc.lkpp.go.id/forum/home/threads?post=1\&threadId=444.

Ghozali, I., \& Latan, H. (2012). Partial Least Square, Konsep Teknik, dan Aplikasi menggunakan program SmartPLS 3.0 untuk Penelitian Empiris. Semarang: Badan Penerbit Universitas Diponegoro.

Hermiyetti. (2010). Pengaruh Penerapan Pengendalian Internal Terhadap Pencegahan Fraud Pengadaan Barang. Jurnal Akuntansi Dan Auditing Indonesia, 4(2), 1-14.

Isnaini, D. B. Y., Nurhaida, T., \& Pratama, I. (2020). Moderating Effect of Supply Chain Dynamic Capabilities on the Relationship of Sustainable Supply Chain Management Practices and Organizational Sustainable Performance: A Study on the Restaurant Industry in Indonesia. Int. J Sup. Chain. Mgt Vol, 9(1), 97-105.

James, S., \& Omulo, E. O. (2018). Agent Based Fraud Detection And Reporting In Public E-Procurement. International Journal of Current Research, 10(11), 75077-75081.

Joseph, O. N., Albert, O., \& Byaruhanga, J. (2015). Effect of Internal Control on Fraud Detection and Prevention in District Treasuries of Kakamega County. International Journal of Business and Management Invention, 4(1), 47-57.

Marbun, D. S., Effendi, S., Lubis, H. Z., \& Pratama, I. (2020). Role of Education Management to Expediate Supply Chain Management: A Case of Indonesian Higher Educational Institutions. Int. J Sup. Chain. Mgt Vol, 9(1), 89-96.

Nedialita, A. (2014). Kinerja Panitia Pengadaan Barang dan Jasa Secara Elektronik (E-Procurement) di Unit Layanan Pengadaan (ULP) Pemerintah Kota Surabaya. Jurnal Kebijakan Dan Manajemen Publik, 1(1), 12-22. 
Njenga, N. M., \& Osiemo. (2013). Effect of fraud risk management on organization performance: A case of deposit-taking microfinance institutions in Kenya. International Journal of Social Sciences and Entrepreneurship, 1(7), 490-507.

Nu'man, A. H., Nurwandi, L., Bachtiar, I., Aspiranti, T., Pratama, I. (2020. Social Networking, and firm performance: Mediating role of comparative advantage and sustainable supply chain. Int. J Sup. Chain. Mgt Vol, 9(3), 664-673.

Nugroho, R. S., Wanto, A. H., \& Trisnawati. (2015). Pengaruh Implementasi Sistem Pengadaan Secara Elektronik (E-Procurement) Terhadap Fraud Pengadaan Barang/Jasa Pemerintah (Studi Pada SKPD Kabupaten Magetan). Jurnal Administrasi Publik, 3(1), 1905-1911.

Nugroho, A., Christiananta, B., Wulani, F., Pratama, I. (2020). Exploring the Association Among Just in Time, Total Quality and Supply Chain Management Influence on Firm Performance: Evidence from Indonesia. Int. J Sup. Chain. Mgt Vol, 9(2), 920-928.

Oduro, I. M., \& Cromwell, A. S. (2018). Internal Control and Fraud Prevention in the Ghanaian Local Government Service. European Journal of Business and Managemen, 10(14), 46-58.

Pratama, I., Che-Adam, N., Kamardin. N. (2019). Corporate social responsibility disclosure (CSRD) quality in Indonesian public listed companies. Polish Journal of Management Studies, 20 (1), 359-371.

Purnamasari, P., \& Amaliah, I. (2015). Fraud Prevention: Relevance to Religiosity and Spirituality in the Workplace. Procedia - Social and Behavioral Sciences, 211(2), 827-835. https://doi.org/10.1016/j.sbspro.2015.11.109

Robbins, R., Glock, C. Y., \& Stark, R. (1994). Religion and Society in Tension. Sociological Analysis (Vol. 27). https://doi.org/10.2307/3710391

Rotchanakitumnuai, S. (2013). The governance evidence of e-government procurement. Transforming Government: People, Process and Policy, 7(3), 309-321. https://doi.org/10.1108/TG-01-2013-0004

Rozmita, D., Yuniarti, R., \& Jabbaar, M. (2015). Pengaruh Pelaksanaan Risk Based Internal Auditing Terhadap Pencegahan Fraud. Jurnal Riset Akuntansi Dan Keuangan Program Studi Akuntansi Fakultas Pendidikan Ekonomi Dan Bisnis Universitas Pendidikan Indonesia, 3(3), 831-836. https://doi.org/http://dx.doi.org/10.17509/jrak.v3i3.6623

Saragih, J., Tarigan, A., Silalahi, E. F., Wardati, J., Pratama, I. (2020). Supply chain operational capability and supply chain operational performance: Does the supply chain management and supply chain integration matters. Int. J Sup. Chain. Mgt Vol, 9(4), 1222-1229.

Saragih, J., Tarigan, A., Pratama, I., Wardati, J., Silalahi, E. F. (2020). The Impact of Total Quality Management, Supply Chain Management Practices and Operations Capability on Firm Performance. Polish Journal of Management Studies, 21 (2), 384-397.

Setyadiharja, R. (2018). E-Procurement (Dinamika Pengadaan Barang/Jasa Elektronik). Yogyakarta: Deepublis.

Sujianto., Yuliani, F., Syofian, Saputra, T, Pratama, I. (2020). The Impact of The Organizational Innovativeness On The Performance Of Indonesian Smes. Polish Journal of Management Studies 2020; 22 (1): 513-530

Sukmadinata, N. S. (2008). Metode Penelitian Pendidikan. Bandung: Remaja Rosdakarya.

Tuanakotta, T. M. (2013). Akuntansi Forensik dan Audit Investigatif. Universitas Stuttgart. Jakarta: Salemba Empat.

Urumsah, D., Valoni, N., \& Asmu'i, F. (2017). Pencegahan Fraud dengan E-Procurenment. Yogyakarta: Ekonesia.

Utami, C. W., Sumaji, Y. M. P., Susanto, H., Septina, F., \& Pratama, I. (2019). Effect of Supply Chain Management Practices on Financial and Economic Sustainable Performance of Indonesian SMEs. Int. J Sup. Chain. Mgt Vol, 8(1), 523-535.

Wicaksono, A. P., \& Urumsah, D. (2016). Factors Influencing Employees To Commit Fraud in Workplace Empirical Study in Indonesian Hospitals. Asia Pacific Fraud Journal, 1(1), 1-18. https://doi.org/10.21532/apfj.001.16.01.01.01 